\title{
Gene expression responses to thermal shifts in the endangered lichen Lobaria pulmonaria
}

\author{
Tania Chavarria Pizarro ${ }^{1}$, Philipp Resl ${ }^{2}$, Aleksandar Janjic ${ }^{1}$, and Silke Werth ${ }^{1}$ \\ ${ }^{1}$ University of Munich \\ ${ }^{2}$ University of Graz
}

June 28, 2021

\begin{abstract}
Anthropogenic climate change has led to unprecedented shifts in temperature across many ecosystems. In a context of rapid environmental changes, acclimation is an important process as it may influence the capacity of organisms to survive under novel thermal conditions. Mechanisms of acclimation could involve upregulation of stress response genes involved in protein folding, DNA damage repair and the regulation of signal transduction genes, along with a simultaneous downregulation of genes involved in growth or cell cycle, in order to maintain cellular functions and equilibria. We transplanted Lobaria pulmonaria lichens originating from different forests to determine the relative effects of long-term acclimation and genetic factors on the variability in expression of mycobiont and photobiont genes. We found a strong response of mycobiont and photobiont to high temperatures, regardless of sample origin. The green-algal photobiont had an overall lower response than the mycobiont. The gene expression of both symbionts was also influenced by acclimation to transplantation sites and by genetic factors. Lobaria pulmonaria seems to have evolved powerful molecular pathways to deal with environmental fluctuations and stress and can acclimate to new habitats by transcriptomic convergence. Although L. pulmonaria has the molecular machinery to counteract short-term thermal stress, survival of lichens like L. pulmonaria depends mostly on their long-term positive carbon balance, which can be compromised by warmer temperatures and reduced precipitation, and both these outcomes have been predicted for Central Europe in connection with global climate change
\end{abstract}

\section{Hosted file}

Chavarria-PizarroTransplantationpaper 06.06.2021.SW Final Draft.docx available at https: //authorea.com/users/422452/articles/528169-gene-expression-responses-to-thermal-shiftsin-the-endangered-lichen-lobaria-pulmonaria

\section{Hosted file}

Figures Transplantation paper 05.10. 2021.docx available at https://authorea.com/users/ 422452/articles/528169-gene-expression-responses-to-thermal-shifts-in-the-endangeredlichen-lobaria-pulmonaria 

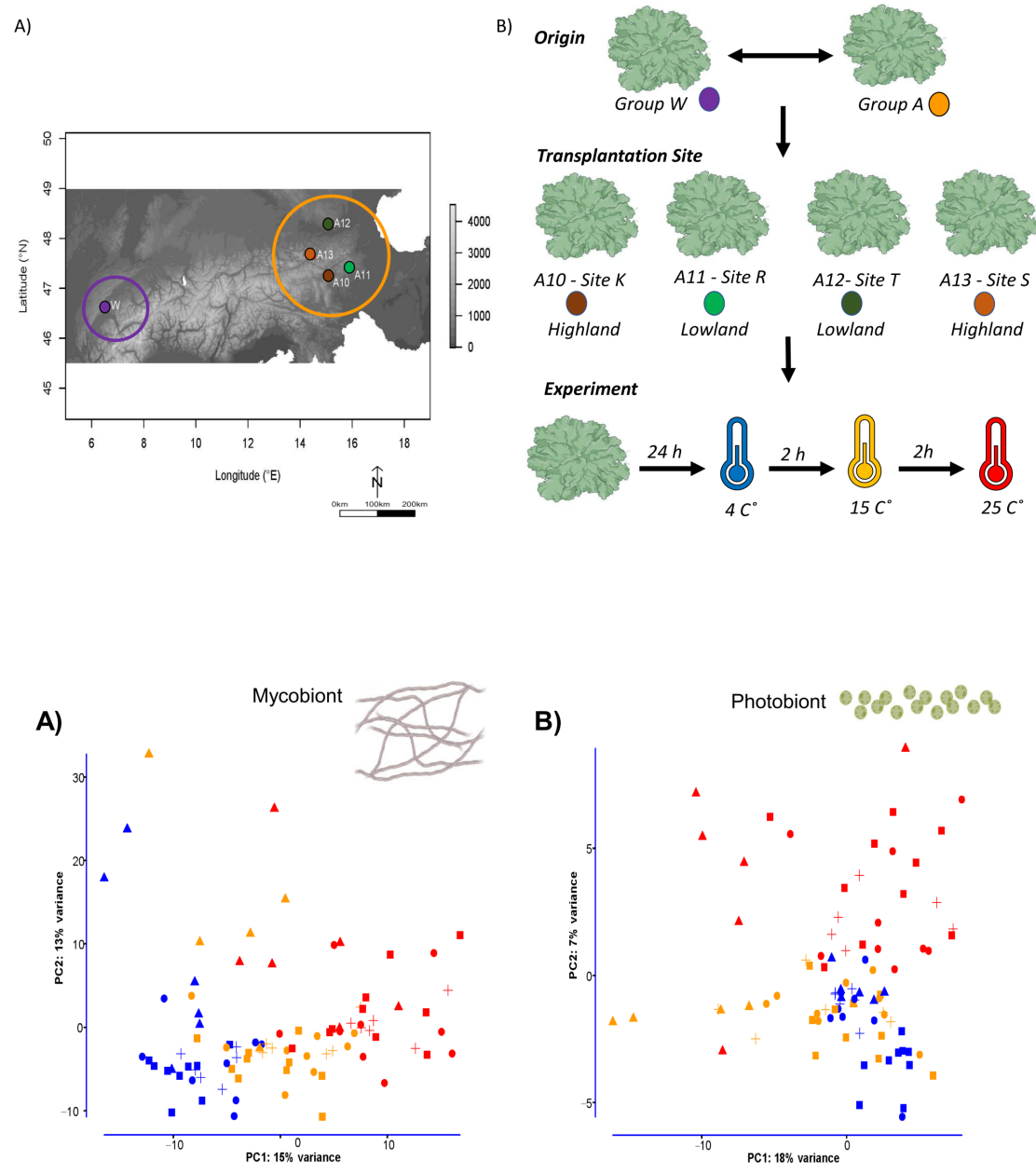

$4 \mathrm{C}^{\circ} 15 \mathrm{C}^{\circ}-25 \mathrm{C}^{\circ}$

OK $\boldsymbol{\Delta} \mathrm{R}+\mathrm{S} \boldsymbol{\mathrm { D }}$

A)

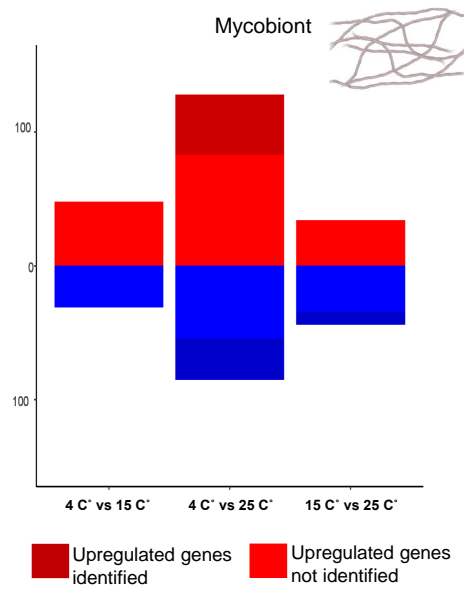

B)

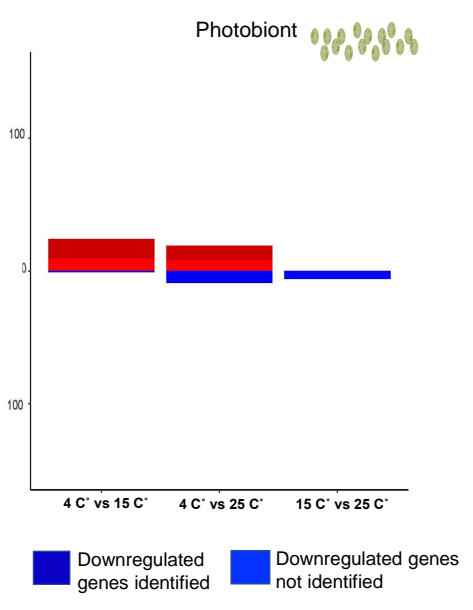




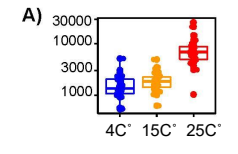

B)

D)

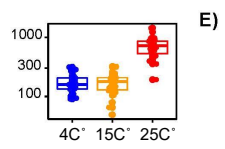

$\underbrace{1000}_{4 \mathrm{C}^{\circ} 15 \mathrm{C}^{\circ} 25 \mathrm{C}^{\circ}}$

F)

G)
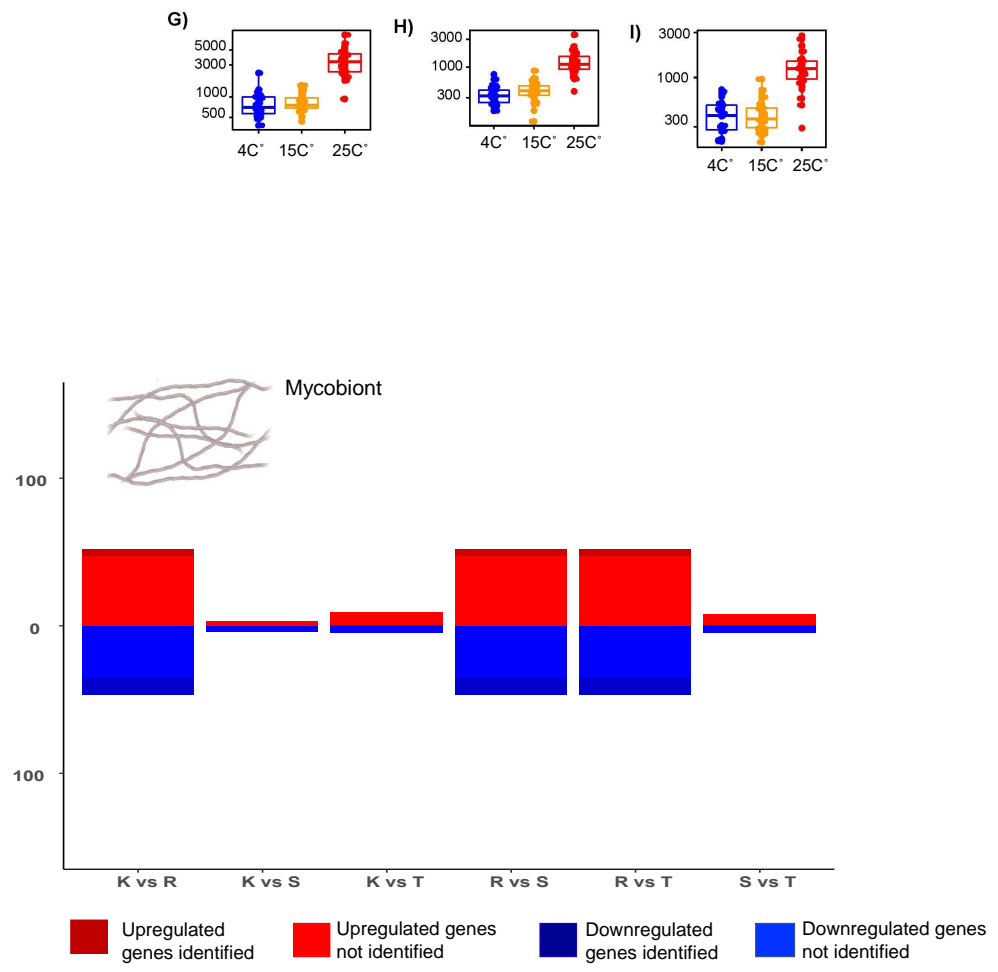

A)
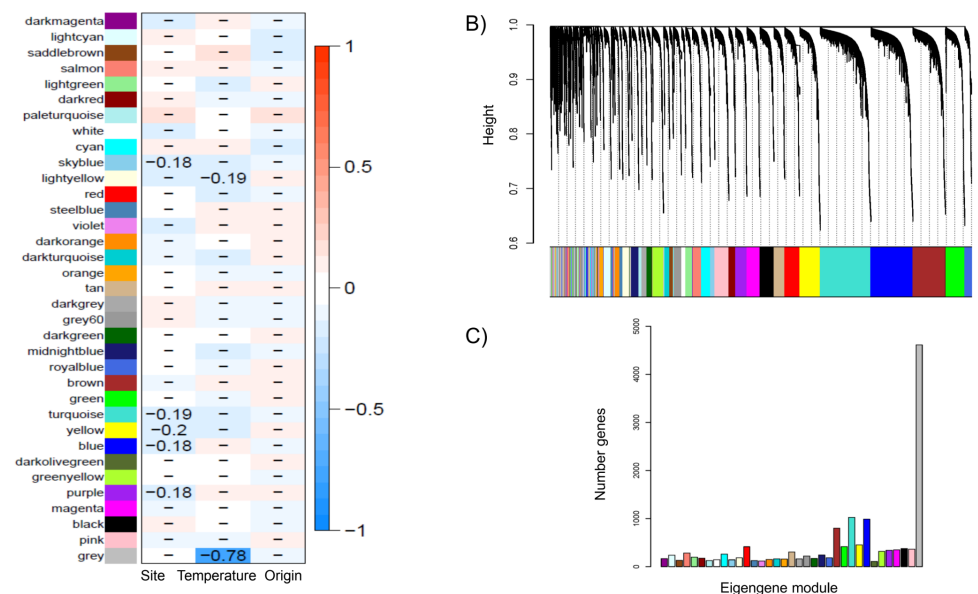

C)

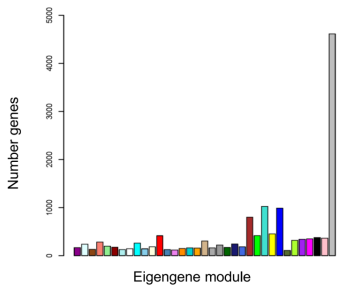



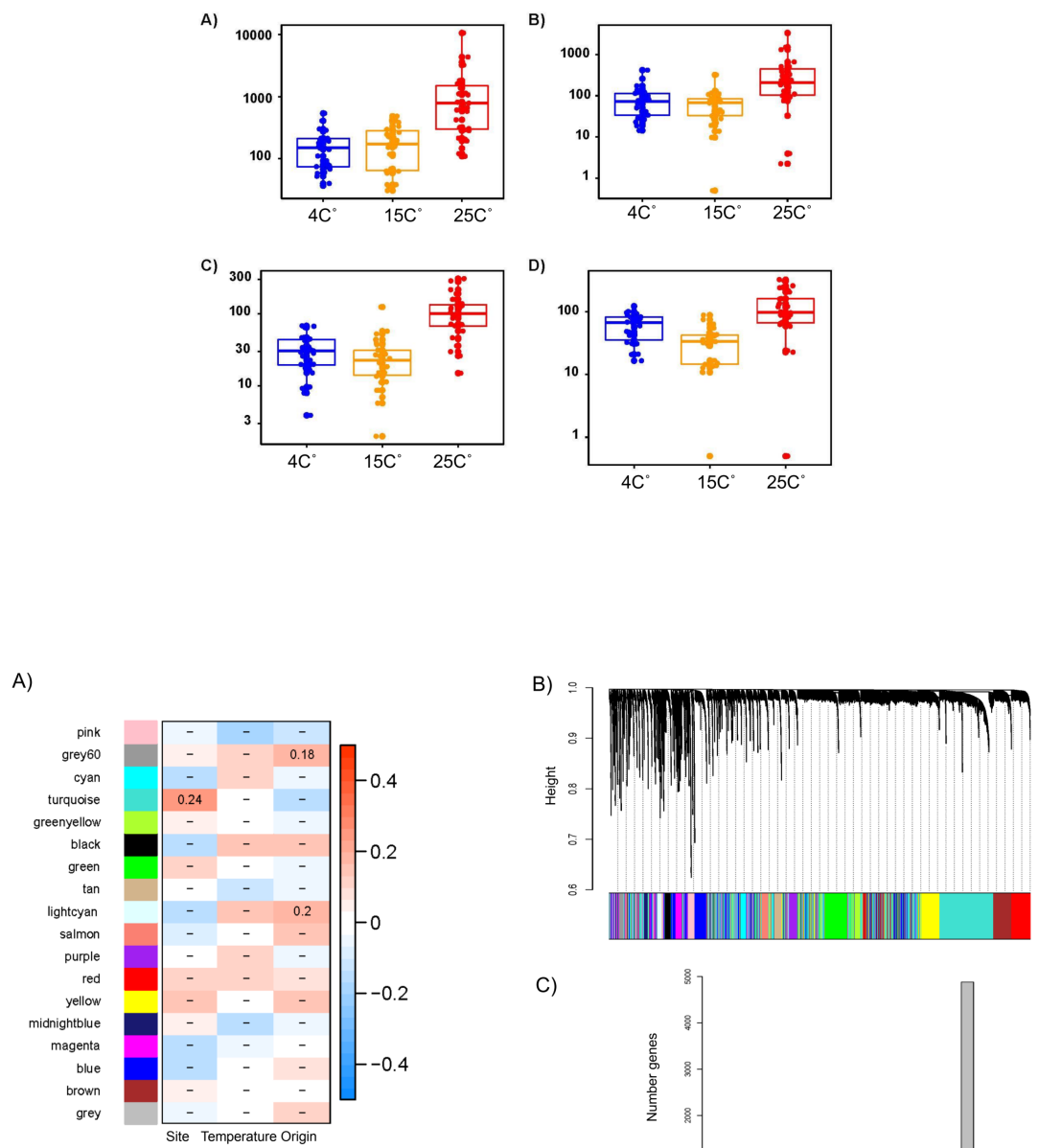

C)

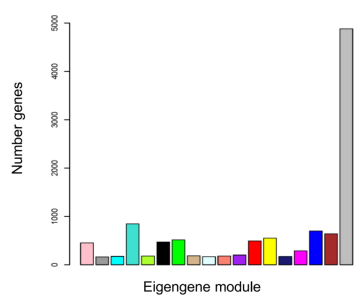

